\title{
Impact of completeness of revascularisation on long-term outcomes in patients with multivessel disease undergoing $\mathrm{PCI}$
}

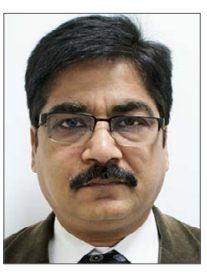

Pravin K. Goel ${ }^{1 *}$, DM, FACC; Ankit Kumar Sahu ${ }^{1}$, DM; Manas Layek ${ }^{1}$, MD;

Roopali Khanna ${ }^{1}, \mathrm{DM}$; Prabhakar Mishra ${ }^{2}, \mathrm{PhD}$

1. Department of Cardiology, Sanjay Gandhi PGIMS, Lucknow, India; 2. Department of Biostatistics \& Health Informatics, Sanjay Gandhi PGIMS, Lucknow, India

This paper also includes supplementary data published online at: www.asiaintervention.org

\section{KEYWORDS}

- drug-eluting stent

- multiple vessel

disease

- percutaneous

coronary

intervention

- revascularisation

strategy

\section{Abstract}

Aims: We aimed to study long-term clinical outcomes in patients with multivessel disease (MVD) undergoing percutaneous coronary intervention (PCI) over the last 10 years with respect to the completeness of revascularisation at a tertiary care hospital.

Methods and results: A total of 2,960 consecutive MVD patients taken for PCI between 2008 to 2017 were enrolled in the study with baseline demographic, procedural, and follow-up details retrieved from custom-made departmental software. Of those, 2,598 patients with follow-up details constituted the study cohort. Complete revascularisation (CR) was achieved in 1,854 (71.4\%) and incomplete revascularisation (IR) in 744 (28.6\%) patients. Propensity matching was performed and 740 matched pairs identified in the two groups. The primary endpoint was survival free of any major adverse cardiovascular events (MACE) with each individual MACE event being a secondary endpoint. IR occurred more often in patients with acute coronary syndrome $(64.1 \%$ vs $58.3 \%, \mathrm{p}=0.003)$, complex lesion intervention $(40.7 \%$ vs $29.6 \%, \mathrm{p}<0.001)$ and in those with mean stent length $\geq 38 \mathrm{~mm}$ per vessel intervened $(21.0 \%$ vs $13.5 \%, \mathrm{p}<0.001)$. Median follow-up was 54 months (interquartile range: 31-84 months). After propensity matching, CR resulted in a better survival free of all adverse events, i.e., $86.4 \%$ vs $81.1 \%$ (HR 1.52, CI: 1.21-2.02; p<0.01). Individual MACE endpoints were, however, not statistically different between the groups.

Conclusions: In MVD patients undergoing PCI, CR results in better survival free of all adverse events including all-cause mortality, non-fatal MI, repeat revascularisation and recurrent angina. 


\section{Abbreviations}

$\begin{array}{ll}\text { ACS } & \text { acute coronary syndrome } \\ \text { ACT } & \text { activated clotting time } \\ \text { CABG } & \text { coronary artery bypass graft surgery } \\ \text { CCS } & \text { Canadian Cardiovascular Society } \\ \text { CKD } & \text { chronic kidney disease } \\ \text { CR } & \text { complete revascularisation } \\ \text { CTO } & \text { chronic total occlusion } \\ \text { EFS } & \text { event-free survival } \\ \text { GDMT } & \text { guideline-directed medical therapy } \\ \text { IQR } & \text { interquartile range } \\ \text { IR } & \text { incomplete revascularisation } \\ \text { LVEF } & \text { left ventricular ejection fraction } \\ \text { MACE } & \text { major adverse cardiovascular events } \\ \text { PCI } & \text { percutaneous coronary intervention } \\ \text { TIMI } & \text { Thrombolysis In Myocardial Infarction }\end{array}$

\section{Introduction}

Complete revascularisation (CR) is a desirable objective but may not sometimes be achievable either by percutaneous coronary intervention (PCI) or coronary artery bypass graft surgery $(\mathrm{CABG})^{1,2}$. Clinical variables including the patient's age, life expectancy, the severity of symptoms at presentation, associated comorbidities, left ventricular function and myocardial viability are often considered in addition to the extent of disease and complexity of coronary anatomy for deciding the mode of revascularisation in an individual case. The resulting completeness of revascularisation is more often an outcome of the case rather than a choice decision and may affect the long-term outcomes ${ }^{3,4}$. At times, incomplete revascularisation (IR) may be life-saving, especially in the ST-elevation myocardial infarction setting considering a comprehensive risk-benefit analysis ${ }^{5,6}$. We aimed to correlate the completeness of revascularisation post PCI with the long-term outcomes in a broad subset of real-world patients with multivessel disease (MVD).

\section{Material and methods}

Data of consecutive patients with multivessel coronary artery disease (CAD) undergoing PCI from January 2008 to December 2017 were included in this single-centre, retrospective cohort study. The decision to perform PCI was based largely on the patient's clinical presentation, lesion characteristics and patient preference, with an aim for CR as far as possible, provided the same could be achieved without a prohibitive risk. Default IR resulted when the operator had planned for a CR procedure but could not achieve the same because of some unexpected intraprocedural difficulties. Elective IR procedures were performed largely in patients with acute coronary syndrome wherein a clear culprit lesion was identifiable and the other vessels or lesions were considered either non-significant or non-amenable to PCI and CABG was not a feasible alternative in that patient for any reason.

A written informed consent was obtained before the procedure from all patients as per the institutional ethics committee approved protocol in accordance with the Declaration of Helsinki ${ }^{7}$. Unfractionated heparin was given at the time of the procedure and titrated to maintain an activated clotting time (ACT) $>250 \mathrm{sec}-$ onds. Glycoprotein IIb/IIIa inhibitors were given at the discretion of the operator, keeping in mind the complexity of the lesion, stent length, use of multiple stents and the patient's clinical status. Post PCI, all patients were prescribed dual antiplatelet therapy for a minimum of 12 months along with guideline-directed medical therapy (GDMT) as a policy. All clinical and procedural details were recorded in a pre-specified custom-made software as part of standard departmental protocol, on a day-to-day basis, which provided the database for this analysis. Patients having an active infection, malignancy or bleeding diathesis were excluded from the study.

\section{DEFINITIONS}

MVD was defined as the presence of $\geq 70 \%$ luminal diameter stenosis in $\geq 2$ major epicardial arteries. Left main disease was considered significant at a $50 \%$ cut-off level. Lesions longer than $10 \mathrm{~mm}$ were considered significant at a $60 \%$ cut-off level. Patients were stratified into two groups, i.e., "complete revascularisation" (CR) and "incomplete revascularisation" (IR). CR was defined as no vessel with a myocardial value of $>1.5$ (which equals a proportional myocardial weight of $10 \%$ of total myocardial weight as per the modified Greenlane System ${ }^{8,9}$ ) and having stenosis of $\geq 70 \%$ being left non-revascularised. IR was defined as at least one or more vessel or a major subdivision with a myocardial value of $>1.5$ with a stenosis of $\geq 70 \%$ being left non-revascularised for any reason. Procedural success was defined as successful dilatation and recanalisation of at least one major epicardial vessel with stent implantation and residual stenosis of $<20 \%$ with at least Thrombolysis In Myocardial Infarction (TIMI) grade 2 flow. Cases amounting to procedural failure were excluded from the study. A residual jeopardy score was obtained after multiplying the myocardial value of the vessel or segment left nonrevascularised with the grade of stenosis left in that vessel (as per the modified Greenlane System ${ }^{8,9}$ ). Patients in whom CR was achieved after two or more staged procedures were included in the CR group only. Procedures were considered staged if performed within the same hospital admission or a stipulated post-discharge period independent of a need generated by a clinical event during the in-between period. The IR group was further sub-categorised and analysed based on a residual jeopardy score as follows: mild IR (residual jeopardy score $\leq 2.0$ ), moderate IR (residual jeopardy score 2.1-5.0) and severe IR (residual jeopardy score $>5.0$ ).

\section{STUDY ENDPOINTS}

The primary endpoint of the study was survival free of any major adverse cardiovascular events (MACE) including all-cause mortality, non-fatal myocardial infarction (MI), need for repeat revascularisation (PCI or $\mathrm{CABG}$ ) and recurrence of or persisting angina of Canadian Cardiovascular Society (CCS) grade 2 or more. Each individual MACE component was considered as a secondary 
endpoint. Any MI/acute coronary syndrome (ACS) event that resulted in death or a repeat revascularisation was included in the said hard endpoint rather than in the MI or recurrence of angina group to avoid duplication.

\section{FOLLOW-UP PROTOCOL}

Follow-up data were obtained at 3 months, 6 months, and then every year as part of a standard follow-up protocol and recorded in the database which had a software-based provision for the same. Incomplete records were refreshed telephonically during the last year of the study period. In each case follow-up was censored at the occurrence of any hard MACE event such as death, non-fatal MI or repeat revascularisation and, in those without a major hard endpoint, time to occurrence of angina was used to censor the follow-up.

\section{STATISTICAL ANALYSIS}

Normality of the variables was assessed, and a variable was considered to be normally distributed when the Z-score was within \pm 3.29 . Continuous variables were expressed as mean \pm standard deviation (SD) or median (interquartile range) and categorical variables were expressed as percentages. An independent samples t-test or the Mann-Whitney $U$ test was used to compare the mean or median values between the groups. The chi-square test was used to test the association between two categorical variables. Kaplan-Meier curves were used to compute cumulative survival of the groups, and the difference in mean and median event-free survival (EFS) time was assessed by log-rank test. Cox regression analysis was employed to evaluate the hazard ratio and $95 \%$ confidence limits with corresponding significance levels. A twotailed p-value of $<0.05$ was considered statistically significant. The analysis was performed using IBM SPSS statistical software, Version 26.0 (IBM Corp., Armonk, NY, USA) and MedCalc statistical software (MedCalc Software Ltd, Ostend, Belgium).

We used propensity score matching to compensate for the potential selection biases. Propensity scores for incomplete revascularisation were computed using a logistic regression model with the resulting revascularisation as a dependent variable and baseline demographic, clinical and angiographic characteristics as independent variables. The variables entered in the model included ACS presentation, left ventricular ejection fraction (LVEF) $<50 \%$, complex lesion intervened and calculated mean stent length per vessel intervened $\geq 38 \mathrm{~mm}$. We matched each patient with incomplete revascularisation to a subject from the completely revascularised group according to the derived propensity variables with a 1:1 ratio.

\section{Results}

A total of 2,960 patients underwent PCI for multivessel CAD during the study period (January 2008 to December 2017). Of these, 362 patients were excluded from the study due to the non-availability of any follow-up data. The remaining 2,598 patients constituted the study cohort. The median follow-up of the study was 54 months with an interquartile range (IQR) of 31 to 84 months (4.5 years; IQR 2.6-7 years). The maximum follow-up was
139 months. Baseline characteristics of all the patients included in the study are summarised in Table 1 . CR could be achieved in $1,854(71.4 \%)$ patients while the remaining 744 (28.6\%) patients had IR. The two groups had an equal proportion of males, elderly, diabetics, hypertensives, smokers, LV dysfunction (LVEF $<50 \%$ ) and chronic kidney disease (CKD) patients. Distribution of twoand three-vessel disease between the groups was also uniform. However, IR group patients had a higher incidence of ACS $(64.1 \%$ vs $58.3 \%$; $=0.003)$, longer mean stent length per vessel intervened $(27.9 \pm 12.6 \mathrm{~mm}$ vs $26.3 \pm 11.3 \mathrm{~mm}$; $\mathrm{p}=0.002)$ and complex lesion intervention $(40.7 \%$ vs $29.6 \%$; $<<0.0001)$ including chronic total occlusions (CTO), left main disease and bifurcation lesions. Multi-staged PCI procedures were significantly more frequent with CR as compared to IR. The mean number of stents implanted per patient was significantly higher in the CR group than in the IR group ( $2.8 \pm 0.7$ vs $1.86 \pm 0.54 ; \mathrm{p}=0.04)$. IR was therefore, as an outcome, observed more often with sicker patients and in those with more complex lesions intervened.

Having identified the significantly different baseline characteristic features between the two groups (CR and IR), a propensitymatched table was derived with 740 matched pairs within the two groups, as shown in Table 2. In the propensity-matched population, there was no difference in the pre-specified outcome deterministic variables in the baseline characteristics.

\section{CLINICAL OUTCOMES}

Table 3 shows the clinical outcomes of the study including the primary endpoint of long-term survival free of any MACE, including death, non-fatal MI, need for repeat revascularisation (PCI or $\mathrm{CABG}$ ) and/or continued angina which was significantly better in the CR group as compared to the IR group ( $86.4 \%$ vs $81.1 \%$; $\mathrm{p}<0.01$ ), at a median follow-up of 4.5 years (Supplementary Table 1). Among the secondary endpoints, there was no significant difference in the incidence of individual MACE events including all-cause mortality $(5.0 \%$ vs $3.6 \% ; \mathrm{p}=0.153)$, non-fatal $\mathrm{MI}(3.5 \%$ vs $3.2 \% ; \mathrm{p}=0.78)$, need for repeat revascularisation $(10.3 \%$ vs $7.8 \% ; \mathrm{p}=0.435)$ and recurrent angina $(10.8 \%$ vs $9.1 \% ; \mathrm{p}=0.066)$ in the IR and CR groups, respectively (Supplementary Table 2).

Kaplan-Meier survival analysis showed the EFS in the two groups to be better with $\mathrm{CR}$ as compared to IR over time (HR 1.52, 95\% CI: 1.21-2.02, $\mathrm{p}<0.01$ ) (Figure 1). Similar curves for individual MACE components including all-cause mortality, repeat revascularisation, non-fatal $\mathrm{MI}$ and recurrence of persistent angina are shown in Figure 2A-Figure 2D, with no significant differences shown between the two groups (Supplementary Table 3).

Among the incompletely revascularised patients, the residual myocardial jeopardy score was $\leq 2.0$ in 163 (22.0\%), 2.1-5.0 in 459 $(62.0 \%)$ and $>5.0$ in only $118(16.0 \%)$ patients (Table 4). Figure 3 shows EFS based on the different grades of incomplete revascularisation revealing a significantly worsening EFS rate with the increasing residual jeopardy score. However, the EFS in patients with mild grades of IR was similar to that seen in patients with CR (HR 1.09, 95\% CI: 0.68-1.72; p=0.729) (Supplementary Table 4). 
Table 1. Baseline characteristics of the entire study cohort $(n=2,598)$ stratified according to the revascularisation strategy.

\begin{tabular}{|c|c|c|c|c|c|}
\hline \multicolumn{2}{|c|}{ Variables } & $\begin{array}{l}\text { Total cohort } \\
(n=2,598)\end{array}$ & $\begin{array}{c}\text { Incomplete } \\
\text { revascularisation } \\
(n=744)\end{array}$ & $\begin{array}{l}\text { Complete } \\
\text { revascularisation } \\
(n=1,854)\end{array}$ & $p$-value \\
\hline \multicolumn{2}{|l|}{ Mean age, years } & $58.71 \pm 10.06$ & $59.1 \pm 9.9$ & $58.6 \pm 10.1$ & 0.237 \\
\hline \multirow[t]{2}{*}{ Sex, n (\%) } & Male & 2,069 (79.6) & 589 (79.2) & $1,480(79.8)$ & \multirow{2}{*}{0.704} \\
\hline & Female & $529(20.4)$ & $155(20.8)$ & $374(20.2)$ & \\
\hline \multirow[t]{3}{*}{ Comorbid risk factors } & Diabetes & $843(32.5 \%)$ & 241 (32.4\%) & 602 (32.5\%) & 0.504 \\
\hline & Hypertension & 906 (34.9\%) & $264(35.5 \%)$ & 642 (34.6\%) & 0.356 \\
\hline & Smoker & $276(10.6 \%)$ & $80(10.6 \%)$ & $196(10.8 \%)$ & 0.471 \\
\hline \multirow[t]{3}{*}{ Clinical presentation } & Stable CAD & $38(1.5 \%)$ & $11(1.5 \%)$ & 27 (1.5\%) & 0.545 \\
\hline & STEMI & 295 (11.4\%) & $89(12.0 \%)$ & $206(11.1 \%)$ & 0.535 \\
\hline & NSTE-ACS & $1,262(48.6 \%)$ & $388(52.2 \%)$ & $874(47.1 \%)$ & 0.021 \\
\hline \multirow[t]{3}{*}{ LVEF } & $<50 \%$ & $630(24.2 \%)$ & $188(25.3 \%)$ & 442 (23.8\%) & \multirow{2}{*}{0.448} \\
\hline & $\geq 50 \%$ & $1,968(75.7 \%)$ & $556(74.7 \%)$ & $1,412(76.2 \%)$ & \\
\hline & Mean, \% & $47.5 \pm 7.7$ & $47.1 \pm 8.5$ & $47.7 \pm 7.4$ & 0.06 \\
\hline \multirow{2}{*}{$\begin{array}{l}\text { No. of vessels } \\
\text { involved }\end{array}$} & 2-vessel disease & $1,714(66 \%)$ & $492(66.1 \%)$ & $1,222(65.9 \%)$ & 0.243 \\
\hline & 3-vessel disease & $884(34 \%)$ & 252 (33.9\%) & $632(34.1 \%)$ & 0.264 \\
\hline \multirow{4}{*}{$\begin{array}{l}\text { Complex lesion } \\
\text { intervened }\end{array}$} & CTO & $456(17.6 \%)$ & $145(19.4 \%)$ & $311(16.8 \%)$ & 0.110 \\
\hline & Left main & $90(3.5 \%)$ & $34(4.6 \%)$ & $56(3.0 \%)$ & 0.057 \\
\hline & Bifurcation lesion & $306(11.8 \%)$ & $124(16.7 \%)$ & $182(9.8 \%)$ & $<0.001$ \\
\hline & Total complex lesion & 852 (32.8\%) & $303(40.7 \%)$ & $549(29.6 \%)$ & $<0.0001$ \\
\hline \multicolumn{2}{|l|}{ Multi-stage procedure } & $202(7.8 \%)$ & $30(4.0 \%)$ & $172(9.3 \%)$ & $<0.001$ \\
\hline \multirow{3}{*}{$\begin{array}{l}\text { No. of vessels } \\
\text { intervened }\end{array}$} & 1 & $94(3.61 \%)$ & $94(12.63 \%)$ & NA & NA \\
\hline & 2 & $1,741(67.0 \%)$ & $481(64.7 \%)$ & $1,260(68.0 \%)$ & 0.432 \\
\hline & $\geq 3$ & $763(29.4 \%)$ & $169(22.7 \%)$ & $594(32.0 \%)$ & 0.049 \\
\hline \multicolumn{2}{|c|}{ No. of vessels intervened per patient } & $2.26 \pm 0.51$ & $2.10 \pm 0.58$ & $2.32 \pm 0.46$ & $<0.001$ \\
\hline \multicolumn{2}{|c|}{ No. of stents implanted per patient } & $2.6 \pm 0.8$ & $1.9 \pm 0.6$ & $2.8 \pm 0.7$ & 0.04 \\
\hline \multicolumn{2}{|c|}{ Total stent length per patient, $\mathrm{mm}$} & $59.1 \pm 26.1$ & $58.4 \pm 29.2$ & $59.4 \pm 24.7$ & 0.385 \\
\hline \multicolumn{2}{|c|}{ Mean stent length per vessel intervened, $\mathrm{mm}$} & $26.8 \pm 11.7$ & $27.9 \pm 12.6$ & $26.3 \pm 11.3$ & 0.002 \\
\hline \multicolumn{2}{|l|}{$<38 \mathrm{~mm}$} & $2,191(84.3 \%)$ & $588(79.0 \%)$ & $1,603(86.5 \%)$ & \multirow{2}{*}{$<0.001$} \\
\hline \multicolumn{2}{|l|}{$\geq 38 \mathrm{~mm}$} & $407(15.7 \%)$ & $156(21.0 \%)$ & $251(13.5 \%)$ & \\
\hline \multicolumn{6}{|c|}{$\begin{array}{l}\text { Plus-minus values are mean } \pm \text { SD. Percentages may not total } 100 \text { because of rounding. CAD: coronary artery disease; CTO: chronic total occlusion; } \\
\text { LVEF: left ventricular ejection fraction; NA: not applicable; NSTE-ACS: non-ST-elevation acute coronary syndrome; PCI: percutaneous coronary } \\
\text { intervention; STEMI: ST-elevation myocardial infarction }\end{array}$} \\
\hline
\end{tabular}

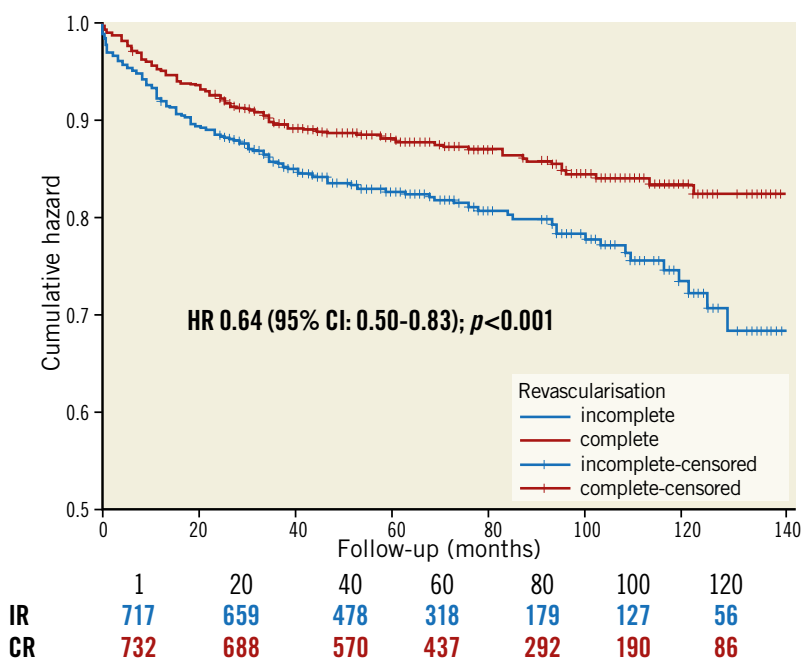

Figure 1. Kaplan-Meier survival curve for multivessel CAD patients treated with DES showing event-free survival of the propensity-matched cohort $(n=1,480)$ with respect to the revascularisation strategy. CAD: coronary artery disease; DES: drug-eluting stent 
Table 2. Baseline characteristics of the propensity-matched cohort $(n=1,480)$ stratified according to the revascularisation strategy.

\begin{tabular}{|c|c|c|c|c|c|}
\hline \multicolumn{2}{|c|}{ Variables } & $\begin{array}{l}\text { Total cohort } \\
(n=1,480)\end{array}$ & $\begin{array}{l}\text { Incomplete } \\
\text { revascularisation } \\
(n=740)\end{array}$ & $\begin{array}{c}\text { Complete } \\
\text { revascularisation } \\
(n=740)\end{array}$ & $p$-value \\
\hline \multicolumn{2}{|l|}{ Mean age, years } & $59.1 \pm 10.0$ & $59.1 \pm 9.9$ & $59.0 \pm 10.1$ & 0.942 \\
\hline \multirow[t]{2}{*}{ Sex, n (\%) } & Male & $1,246(84.2)$ & 589 (79.2) & $660(89.6)$ & \multirow{2}{*}{$<0.001$} \\
\hline & Female & $234(15.8)$ & $151(20.4)$ & $80(10.8)$ & \\
\hline \multirow[t]{3}{*}{ Comorbid risk factors } & Diabetes & $481(32.5 \%)$ & $240(32.4 \%)$ & $241(32.6 \%)$ & 0.998 \\
\hline & Hypertension & $516(34.9 \%)$ & $263(35.5 \%)$ & $253(34.2 \%)$ & 0.624 \\
\hline & Smoker & $157(10.6 \%)$ & $78(10.5 \%)$ & $79(10.7 \%)$ & 0.998 \\
\hline \multirow[t]{3}{*}{ Clinical presentation } & Stable CAD & $32(2.2 \%)$ & $11(1.5 \%)$ & $21(2.8 \%)$ & 0.106 \\
\hline & STEMI & $178(12.0 \%)$ & $97(13.1 \%)$ & $81(10.9 \%)$ & 0.201 \\
\hline & NSTE-ACS & $776(52.4 \%)$ & $380(51.4 \%)$ & $396(53.5 \%)$ & 0.407 \\
\hline \multicolumn{2}{|l|}{ Mean LVEF, \% } & $46.1 \pm 8.9$ & $47.0 \pm 8.5$ & $45.1 \pm 9.2$ & $<0.001$ \\
\hline \multicolumn{2}{|l|}{ LVEF $<50 \%$} & $374(25.3 \%)$ & $187(25.3 \%)$ & $187(25.3 \%)$ & \multirow{2}{*}{0.998} \\
\hline \multicolumn{2}{|l|}{ LVEF $\geq 50 \%$} & $1,106(74.7 \%)$ & $553(74.7 \%)$ & $553(74.7 \%)$ & \\
\hline \multicolumn{2}{|c|}{ Complex lesion intervened } & $534(36.1 \%)$ & $267(36.1 \%)$ & $267(36.1 \%)$ & 0.998 \\
\hline \multicolumn{2}{|l|}{ СТO } & 309 (20.9\%) & $142(19.2 \%)$ & $167(22.6 \%)$ & 0.125 \\
\hline \multicolumn{2}{|l|}{ Left main } & $64(4.3 \%)$ & $33(4.5 \%)$ & $31(4.2 \%)$ & 0.898 \\
\hline \multicolumn{2}{|l|}{ Bifurcation lesion } & $220(14.9 \%)$ & $123(16.6 \%)$ & $97(13.1 \%)$ & 0.068 \\
\hline \multicolumn{2}{|l|}{ Multi-stage procedure } & $115(7.8 \%)$ & $30(4.1 \%)$ & 85 (11.5\%) & $<0.001$ \\
\hline \multicolumn{2}{|c|}{ Total stent length per patient, $\mathrm{mm}$} & $62.3 \pm 29.1$ & $58.3 \pm 29.2$ & $66.3 \pm 28.4$ & $<0.001$ \\
\hline \multicolumn{2}{|c|}{ Mean stent length per vessel intervened, $\mathrm{mm}$} & $27.7 \pm 13.1$ & $27.8 \pm 12.6$ & $27.6 \pm 13.6$ & 0.685 \\
\hline \multicolumn{2}{|l|}{$<38 \mathrm{~mm}$} & $1,176(79.5 \%)$ & $588(79.5 \%)$ & $588(79.5 \%)$ & \multirow{2}{*}{0.998} \\
\hline \multicolumn{2}{|l|}{$\geq 38 \mathrm{~mm}$} & $304(20.5 \%)$ & $152(20.5 \%)$ & $152(20.5 \%)$ & \\
\hline \multicolumn{6}{|c|}{$\begin{array}{l}\text { Plus-minus values are mean } \pm \text { SD. Percentages may not total } 100 \text { because of rounding. CAD: coronary artery disease; CTO: chronic total occlusion; } \\
\text { LVEF: left ventricular ejection fraction; NA: not applicable; NSTE-ACS: non-ST-elevation acute coronary syndrome; PCI: percutaneous coronary } \\
\text { intervention; STEMI: ST-elevation myocardial infarction }\end{array}$} \\
\hline
\end{tabular}

\section{Discussion}

The key observations in our "real-world" study of PCI in MVD in a broad group of patients include, firstly, a better long-term eventfree survival free of any MACE including death, non-fatal MI, the need for repeat revascularisation and recurrent or residual angina in the CR group when compared to IR. Secondly, there were no significant differences in the individual MACE components including all-cause mortality, non-fatal MI and the need for repeat revascularisation between the groups. Thirdly, there was a marginally significant higher incidence of recurrent or residual angina in patients with IR. Lastly, there was an absolute survival free of any adverse event in excess of $80 \%$ at a median follow-up duration of 4.5 years, even in patients with IR, and survival free of MACE in patients with mild grades of IR (jeopardy score $<2.0$ ) was no different from those with CR.

Prior studies have shown conflicting results when evaluating long-term outcomes following complete and incomplete revascularisation in multivessel CAD. Although the majority of data ${ }^{10-21}$ favours $\mathrm{CR}$, there are a few studies which showed that $\mathrm{CR}$ alone may not improve long-term clinical outcomes in patients with

Table 3. Clinical outcomes in the propensity-matched cohort.

\begin{tabular}{|c|c|c|c|c|c|c|}
\hline \multirow{2}{*}{ Outcome $(n=1,480)$} & \multicolumn{2}{|c|}{$\begin{array}{l}\text { Incomplete revascularisation } \\
\qquad(\mathrm{n}=740)\end{array}$} & \multicolumn{2}{|c|}{$\begin{array}{l}\text { Complete revascularisation } \\
\qquad(n=740)\end{array}$} & \multirow{2}{*}{$\begin{array}{c}\text { Hazard ratio } \\
\text { (95\% CI) (IR vs CR) }\end{array}$} & \multirow{2}{*}{$p$-value } \\
\hline & no. $(\%)$ & $\%$ per person/yr & no. (\%) & $\%$ per person/yr & & \\
\hline Survival free of any MACE & $600(81.1)$ & 18.0 & $639(86.4)$ & 19.2 & $0.64(0.50-0.83)$ & $<0.01$ \\
\hline Occurrence of at least one MACE & $140(18.9)$ & 4.2 & $101(13.6)$ & 3.0 & $1.56(1.21-2.02)$ & $<0.01$ \\
\hline All-cause mortality & $37(5.0)$ & 1.1 & 27 (3.6) & 0.8 & $1.44(0.87-2.36)$ & 0.153 \\
\hline Non-fatal MI & $24(3.2)$ & 0.7 & $26(3.5)$ & 0.8 & $1.08(0.62-1.88)$ & 0.788 \\
\hline Repeat revascularisation & $58(7.8)$ & 1.7 & $76(10.3)$ & 2.3 & $0.87(0.62-1.23)$ & 0.435 \\
\hline Recurrent angina & $80(10.8)$ & 2.4 & $67(9.1)$ & 2.0 & $1.34(0.97-1.85)$ & 0.066 \\
\hline
\end{tabular}



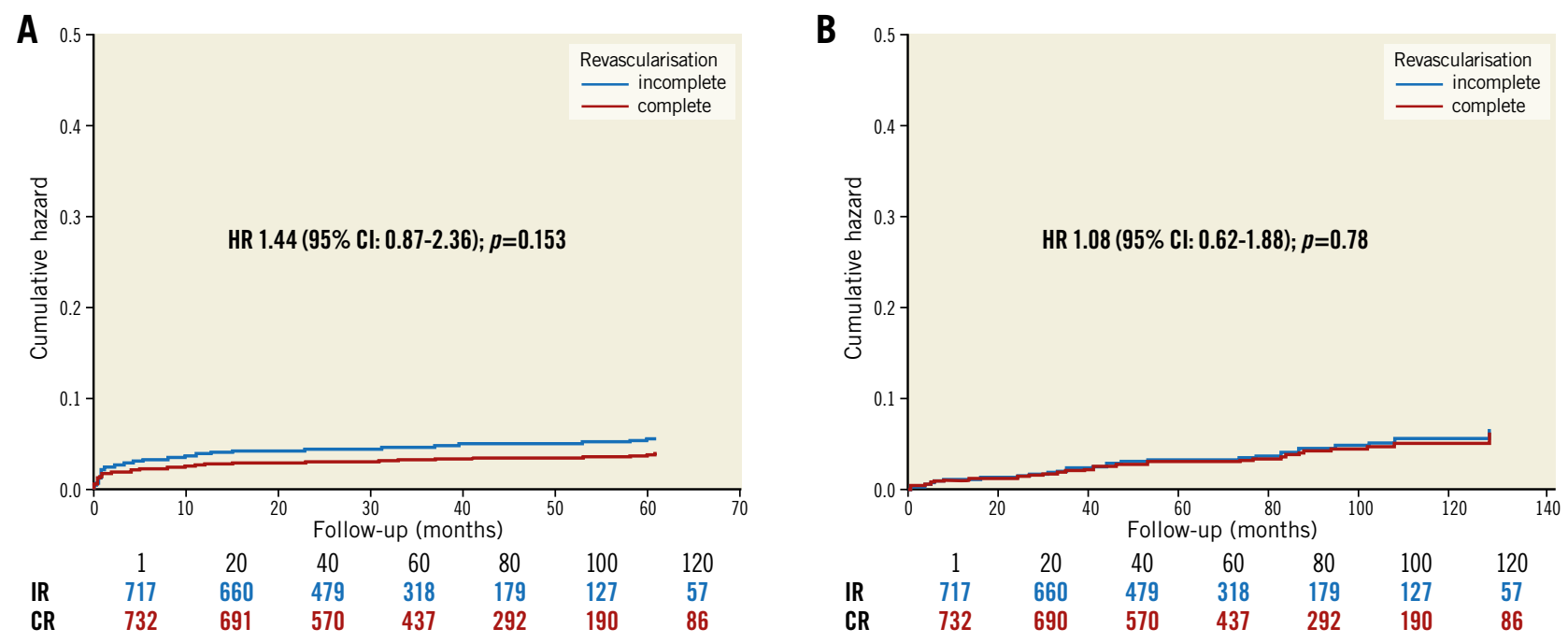

$\begin{array}{lccccccc} & 1 & 20 & 40 & 60 & 80 & 100 & 120 \\ \text { IR } & 717 & 660 & 479 & 318 & 179 & 127 & 57 \\ \text { CR } & 732 & 690 & 570 & 437 & 292 & 190 & 86\end{array}$
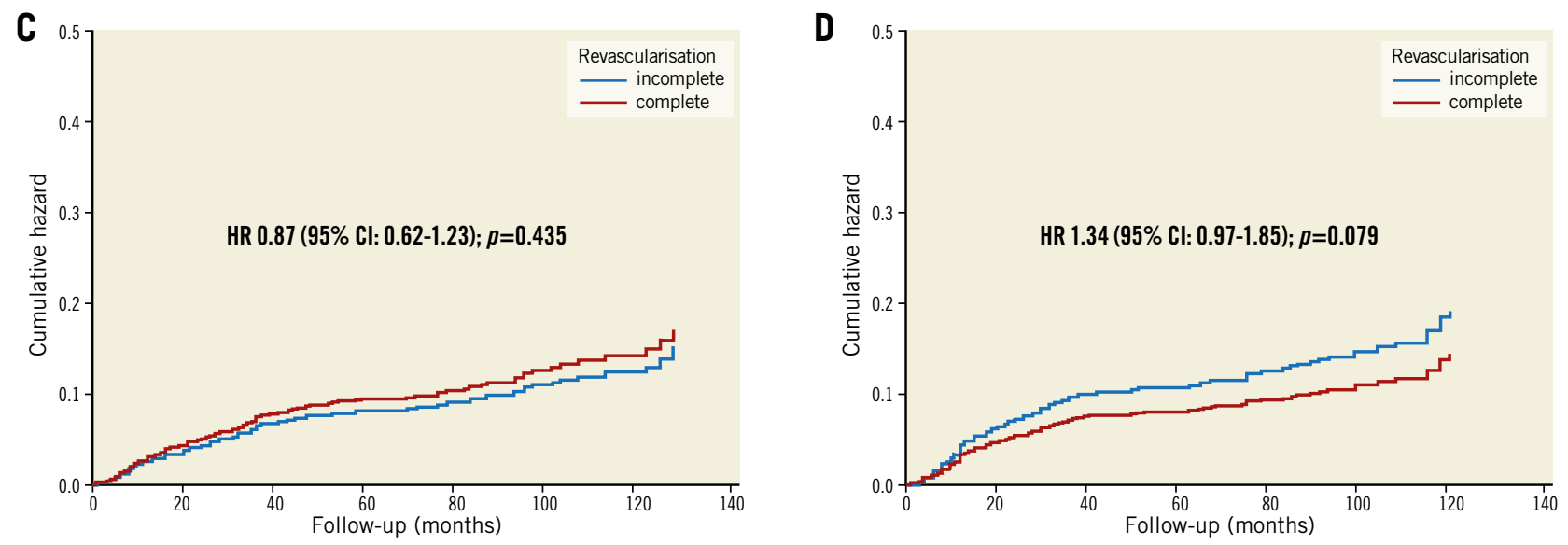

$\begin{array}{lccccccc} & 1 & 20 & 40 & 60 & 80 & 100 & 120 \\ \text { IR } & 718 & 661 & 480 & 319 & 180 & 127 & 57 \\ \text { CR } & 732 & 691 & 570 & 437 & 292 & 190 & 86\end{array}$

$\begin{array}{lccccccc} & 1 & 20 & 40 & 60 & 80 & 100 & 120 \\ \text { IR } & 717 & 658 & 477 & 318 & 179 & 126 & 56 \\ \text { CR } & 732 & 683 & 568 & 437 & 291 & 190 & 85\end{array}$

Figure 2. Cox proportional hazard plot in the propensity-matched cohort $(n=1,480)$ showing the cumulative incidence of individual components of MACE. A) All-cause mortality. B) Non-fatal myocardial infarction. C) Repeat revascularisation. D) Recurrent/persistent angina. MACE: major adverse cardiovascular events

MVD $^{3,4,22}$. In a single-centre propensity-matched cohort, Chang et $\mathrm{al}^{4}$ compared outcomes in those with $\mathrm{CR}$ versus IR and found that there was no significant difference in the primary outcome of all-cause mortality $(8.6 \%$ vs $9.0 \%$; HR 1.03 , $95 \%$ CI:
$0.80-1.32, \mathrm{p}=0.83$ ), as well as in the secondary outcomes of stroke and repeat revascularisation. Kim et $\mathrm{al}^{3}$ showed that $\mathrm{CR}$ alone did not improve long-term outcomes in patients with MVD and hypothesised the need for ischaemia-guided revascularisation.

Table 4. MACE rates of IR groups in propensity-matched cohort compared with CR group classification according to residual jeopardy score.

\begin{tabular}{|c|c|c|c|c|c|}
\hline \multirow{2}{*}{$\begin{array}{c}\text { Grade of IR } \\
\text { (jeopardy score) }\end{array}$} & \multirow{2}{*}{$\begin{array}{c}\text { No. of patients } \\
\text { (total IR=740) n (\%) }\end{array}$} & \multicolumn{2}{|c|}{ MACE rate } & \multirow{2}{*}{$\begin{array}{c}\text { Hazard ratio } \\
\text { (95\% CI) (IR vs CR) }\end{array}$} & \multirow{2}{*}{$\begin{array}{c}p \text {-value } \\
\text { (compared to CR) }\end{array}$} \\
\hline & & no. (\%) & $\%$ per person/yr & & \\
\hline Mild IR $(<2.0)$ & $163(22.0)$ & $22(13.4)$ & 3.0 & $1.09(0.68-1.72)$ & 0.729 \\
\hline Moderate IR (2.1-5.0) & 459 (62.0) & $93(20.2)$ & 4.5 & $1.63(1.23-2.17)$ & 0.001 \\
\hline Severe IR $(>5.0)$ & $118(16.0)$ & $27(22.7)$ & 5.0 & $1.99(1.29-3.06)$ & 0.002 \\
\hline \multicolumn{6}{|c|}{$\begin{array}{l}\text { Intra IR group comparison ( } \boldsymbol{p} \text {-values): } \\
\text { Mild IR }(<2.0) \text { vs moderate IR }(2.1-5.0)=0.084 \\
\text { Mild IR }(<2.0) \text { vs severe IR }(>5.0)=0.037 \\
\text { Moderate IR }(2.1-5.0) \text { vs severe IR }(>5.0)=0.337\end{array}$} \\
\hline
\end{tabular}




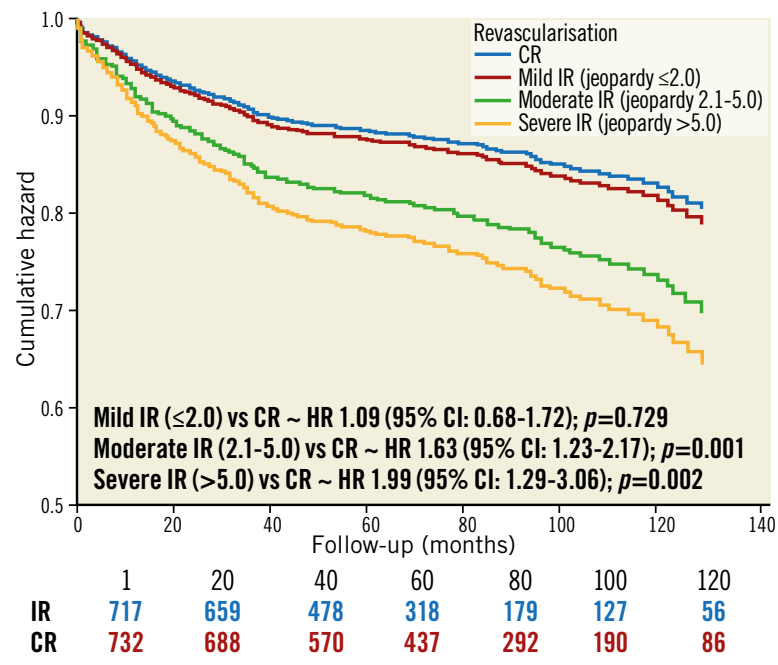

Figure 3. Kaplan-Meier survival curve for multivessel CAD patients treated with DES showing event-free survival of incompletely revascularised patients ( $n=740$ ) classified according to the residual jeopardy score post PCI as compared to the complete revascularisation strategy. CAD: coronary artery disease; DES: drug-eluting stent; PCI: percutaneous coronary intervention

In a real-world setting, however, CR is something which, although being desirable, may not be achievable even with CABG let alone PCI because of several clinical and anatomical barriers. Gössl et $\mathrm{al}^{2}$ found that CR was achieved in only $57 \%$ of patients undergoing PCI as compared to $67 \%$ in patients undergoing CABG, highlighting that, although CABG may achieve more CR than PCI, a good proportion are still left with IR with CABG too. In our study, IR was more frequently observed in patients presenting with ACS or in those where complex coronary lesions were intervened or longer stents were used. At times, achieving true CR may mandate intervention in vessels with relatively low myocardial value having complex lesions wherein the effort required may be so high that the risk/benefit ratio may not be in favour. This is supported by our observation that it was only in the presence of moderate to severe IR (jeopardy score $>2.0$ ) that total EFS was better with $\mathrm{CR}$ than with IR, with almost no difference between those with mild IR and CR. This observation also highlights the importance of objectivising the grade of IR. It can be surmised, then, that mild grades of IR (jeopardy score $\leq 2.0$ ), as produced by, say, a non-revascularised diagonal, a small obtuse marginal (OM) or a posterior descending artery (PDA) alone, may not be worth the chase if other haemodynamically important vessels have been taken care of. Also, if as an alternative these patients were advised surgery so as to obtain a true CR one still cannot be certain of, firstly, whether CR would always be achieved, especially with these smaller vessels being overlooked by the surgeon too and, secondly, what the true benefit of the same would be, taking into consideration the morbidity of surgery. This further strengthens the importance of a detailed angiographic analysis including an assessment of the myocardial value of each vessel segment being left non-revascularised and the generated residual myocardial jeopardy score that has not been brought out by most prior studies. Our study, however, has brought out this residual jeopardy to its utmost precision by objectively assessing the completeness or incompleteness of revascularisation in each individual case using the modified Greenlane System ${ }^{8,9}$ of angiographic analysis which includes all these calculations.

Some of the recent data from trials such as COMPLETE ${ }^{23}$ favours $\mathrm{CR}$ as a strategy but this is largely in the acute ST-elevation myocardial infarction (STEMI) setting alone ${ }^{24-28}$. Moreover, several previous trials ${ }^{6,29}$ on similar patient subsets have also advocated culprit vessel PCI only as a strategy, which truly is an IR strategy trying to tide over the unstable phase of these sick patients. In several other studies ${ }^{5,30,31}$, staged revascularisation has been included in culprit vessel PCI or an IR strategy only, which theoretically may not be completely correct because for the long-term outcomes this patient is finally completely revascularised. However, as our study included a broad spectrum of patients, it may be difficult to comment on the impact of completeness of revascularisation specifically in the STEMI subset.

Despite the existing differences observed among various observational studies, large meta-analyses ${ }^{32-36}$ have suggested a significant benefit of CR over IR, including a relative reduction of approximately $30 \%$ in mortality. We, on the other hand, did find a better EFS with a CR strategy but without any difference in mortality outcomes. This could be related to the strict definitions of CR and IR based on our very detailed objective assessment of diagnostic angiograms, including the use of jeopardy scores to classify the degree of IR. Also, the majority (84\%) of IR patients had only mild to moderate grades of IR (jeopardy score $\leq 5.0$ ). A residual jeopardy score in excess of 5.0 (equivalent to about one third of the total myocardial weight being left non-revascularised) was observed in only $16 \%$ of the total IR group. This could be because the majority of our patients were accepted with the aim of complete revascularisation except for selected ACS patients where a clear culprit was identifiable and non-culprit vessels were largely non-revascularisable.

Also, ours is a retrospective analysis of recorded patient data rather than a prospective randomised study, with IR being more an outcome than an elective pre-determined strategy. A prospective CR or IR strategy by choice truly may not be possible without a clearly identifiable culprit lesion, as noted in the ACS (STEMI or NSTE-ACS) setting. Also, in day-to-day clinical practice, because CR may not always be achievable and often one may have to accept IR with a certain grade of residual myocardial jeopardy as per the clinical setting, our results could be seen in a different light. That is, despite IR, at least $80 \%$ of patients could have a median survival free of MACE of more than 4.5 years and no worsening of mortality outcomes as compared to the CR group. This is an outcome which, in absolute terms, may not be bad at all considering the complexity of the study group patients with nearly $60 \%$ having ACS and at least $40 \%$ of patients having one or more complex lesions intervened including CTO, bifurcation, 
or left main, lesion subgroups which were not included in several other trials. A large multicentric prospective randomised clinical trial aiming at IR versus CR while preferable from a methodological standpoint would truly be difficult or nearly impossible to execute except in a STEMI setting.

\section{Study limitations}

This being a real-world single-centre study, it could be biased in terms of the criteria considered for revascularisation decision making, which may not be reproducible in other patient populations. Secondly, being an observational study and a retrospective analysis, it may be fraught with all the inherent weaknesses of any such analysis. However, the strength is the meticulous angiographic analysis and prospective recording of data on a day-to-day basis which gives it authenticity. Thirdly, being a single-centre/single primary operator-based study does give it an advantage of uniformity of case types and at least shows what at best or at worst could be possible. Also, documentation of reversible ischaemia was not carried out objectively and decisions were based on clinical judgement alone. Lastly, cerebrovascular stroke and major/ minor bleeding events were not included in the study outcome/ endpoints which is often done for studies of this type. This was primarily because our software did not have this included as one of the observational endpoints right at the beginning when the software was customised before the study conceptualisation.

\section{Conclusions}

In patients with MVD undergoing PCI, complete revascularisation results in better survival free of any adverse event including all-cause mortality, MI, repeat revascularisation or recurrent angina but with no significant difference in any of the individual MACE endpoints.

\section{Impact on daily practice}

A selective strategy of incomplete revascularisation could be beneficial in some of the sicker real-world patients with complex multivessel disease wherein, although long-term survival free of all adverse events would possibly be better with complete revascularisation in relative terms, in absolute terms the difference may not be a large one, i.e., a 5.3\% difference in total event-free survival over a median follow-up of 4.5 years, and no significant difference in all-cause mortality between the two groups. The difference is driven largely by a marginally significant increased residual angina in the incomplete revascularisation group.

\section{Acknowledgement}

We acknowledge the contribution of Mr Mritunjay Mishra, Research Assistant in the Department of Cardiology, SGPGIMS, for data collection, telephonic follow-ups and documentation of records.

\section{Conflict of interest statement}

The authors have no conflicts of interest to declare.

\section{References}

1. Ahn JM, Park DW, Lee CW, Chang M, Cavalcante R, Sotomi Y, Onuma Y, Tenekecioglu E, Han M, Lee PH, Kang SJ, Lee SW, Kim YH, Park SW, Serruys PW, Park SJ. Comparison of Stenting Versus Bypass Surgery According to the Completeness of Revascularization in Severe Coronary Artery Disease: PatientLevel Pooled Analysis of the SYNTAX, PRECOMBAT, and BEST Trials. JACC Cardiovasc Interv. 2017;10:1415-24.

2. Gössl M, Faxon DP, Bell MR, Holmes DR, Gersh BJ. Complete versus incomplete revascularization with coronary artery bypass graft or percutaneous intervention in stable coronary artery disease. Circ Cardiovasc Interv. 2012;5:597-604.

3. Kim YH, Park DW, Lee JY, Kim WJ, Yun SC, Ahn JM, Song HG, Oh WJ, Park JS, Kang SJ, Lee SW, Lee CW, Park SW, Park SJ. Impact of angiographic complete revascularization after drug eluting stent implantation or coronary artery bypass surgery for multivessel coronary artery disease. Circulation. 2011;123:2373-81.

4. Chang M, Ahn JM, Kim N, Lee PH, Roh JH, Yoon SH, Kang SJ, Lee SW, Kim YH, Lee CW, Park SW, Park DW, Park SJ. Complete versus incomplete revascularization in patients with multivessel coronary artery disease treated with drug-eluting stents. Am Heart J. 2016;179:157-65.

5. Politi L, Sgura F, Rossi R, Monopoli D, Guerri E, Leuzzi C, Bursi F, Sangiorgi GM, Modena MG. A randomized trial of targetvessel versus multi-vessel revascularisation in ST-elevation myocardial infarction: major adverse cardiac events during long-term follow-up. Heart. 2010;96:662-7.

6. Ghani A, Dambrink JH, van 't Hof AW, Ottervanger JP, Gosselink AT, Hoorntje JC. Treatment of non-culprit lesions detected during primary PCI: long-term follow-up of a randomized clinical trial. Neth Heart J. 2012;20:347-53.

7. World Medical Association. World Medical Association Declaration of Helsinki: ethical principles for medical research involving human subjects. JAMA. 2013;310:2191-4.

8. Brandt PW, Partridge JB, Wattie WJ. Coronary arteriography; method of presentation of the arteriogram report and a scoring system. Clin Radiol. 1977;28:361-5.

9. Goel PK. A relook at the reporting of coronary angiograms in the interventional era: a perspective. Indian Heart J. 1997;49:323-6.

10. Hannan EL, Racz M, Holmes DR, King SB 3rd, Walford G, Ambrose JA, Sharma S, Katz S, Clark LT, Jones RH. Impact of completeness of percutaneous coronary intervention revascularization on long-term outcomes in the stent era. Circulation. 2006;113: 2406-12.

11. Hambraeus K, Jensevik K, Lagerqvist B, Lindahl B, Carlsson R, Farzaneh-Far R, Kellerth T, Omerovic E, Stone G, Varenhorst C, James S. Long-Term Outcome of Incomplete Revascularization After Percutaneous Coronary Intervention in SCAAR (Swedish Coronary Angiography and Angioplasty Registry). JACC Cardiovasc Interv. 2016;9:207-15.

12. McLellan CS, Ghali WA, Labinaz M, Davis RB, Galbraith PD, Southern DA, Shrive FM, Knudtson ML; Alberta Provincial Project for Outcomes Assessment in Coronary Heart Disease (APPROACH) 
Investigators. Association between completeness of percutaneous coronary revascularization and post-procedure outcomes. Am Heart J. 2005;150:800-6.

13. Gao Z, Xu B, Yang YJ, Yuan JQ, Chen J, Chen JL, Qiao SB, Wu YJ, Yan HB, Gao RL. Long-term outcomes of complete versus incomplete revascularization after drug-eluting stent implantation in patients with multivessel coronary disease. Catheter Cardiovasc Interv. 2013;82:343-9.

14. Wu C, Dyer AM, Walford G, Holmes DR Jr, King SB 3rd, Stamato NJ, Sharma S, Jacobs AK, Venditti FJ, Hannan EL. Incomplete revascularization is associated with greater risk of longterm mortality after stenting in the era of first-generation drug-eluting stents. Am J Cardiol. 2013;112:775-81.

15. Vieira RD, Hueb W, Gersh BJ, Lima EG, Pereira AC, Rezende PC, Garzillo CL, Hueb AC, Favarato D, Soares PR, Ramires JA, Kalil Filho R. Effect of complete revascularization on 10-year survival of patients with stable multivessel coronary artery disease: MASS II trial. Circulation. 2012;126:S158-63.

16. Lehmann R, Fichtlscherer S, Schachinger V, Held L, Hobler C, Baier G, Zeiher AM, Spyridopoulos I. Complete revascularization in patients undergoing multivessel $\mathrm{PCI}$ is an independent predictor of improved long-term survival. J Interv Cardiol. 2010;23:256-63.

17. Tamburino C, Angiolillo DJ, Capranzano P, Dimopoulos K, La Manna A, Barbagallo R, Tagliareni F, Mangiafico S, Guzman LA, Galassi AR, Bass TA. Complete versus incomplete revascularization in patients with multivessel disease undergoing percutaneous coronary intervention with drug-eluting stents. Catheter Cardiovasc Interv. 2008;72:448-56.

18. Head SJ, Mack MJ, Holmes DR Jr, Mohr FW, Morice MC, Serruys PW, Kappetein AP. Incidence, predictors and outcomes of incomplete revascularization after percutaneous coronary intervention and coronary artery bypass grafting: a sub-group analysis of 3-year SYNTAX data. Eur J Cardiothorac Surg. 2012;41:535-41.

19. Goel PK, Khanna R, Pandey CM, Ashfaq F. Long-term outcomes post chronic total occlusion intervention-implications of completeness of revascularization. J Interv Cardiol. 2018;31: 293-301.

20. Li J, Schindler TH, Qiao S, Wei H, Tian Y, Wang W, Zhang X, Yang X, Liu X. Impact of incomplete revascularization of coronary artery disease on long-term cardiac outcomes: retrospective comparison of angiographic and myocardial perfusion imaging criteria for completeness. J Nucl Cardiol. 2015;23:546-55.

21. Chung JW, Park KH, Lee MH, Park KW, Park JS, Kang HJ, Koo BK, Kwon YW, Kim HS. Benefit of complete revascularization in patients with multivessel coronary disease in the drug-eluting stent era. Circ J. 2012;76:1624-30.

22. Ijsselmuiden AJ, Ezechiels J, Westendorp IC, Tijssen JG, Kiemeneij F, Slagboom T, van der Wieken R, Tangelder G, Serruys PW, Laarman G. Complete versus culprit vessel percutaneous coronary intervention in multivessel disease: a randomized comparison. Am Heart J. 2004;148:467-74.

23. Mehta SR, Wood DA, Storey RF, Mehran R, Bainey KR, Nguyen H, Meeks B, Di Pasquale G, López-Sendón J, Faxon DP,
Mauri L, Rao SV, Feldman L, Steg PG, Avezum Á, Sheth T, PinillaEcheverri N, Moreno R, Campo G, Wrigley B, Kedev S, Sutton A, Oliver R, Rodés-Cabau J, Stanković G, Welsh R, Lavi S, Cantor WJ, Wang J, Nakamya J, Bangdiwala SI, Cairns JA; COMPLETE Trial Steering Committee and Investigators. Complete revascularization with multivessel PCI for myocardial infarction. $N$ Engl J Med. 2019;381:1411-21.

24. Wald DS, Morris JK, Wald NJ, Chase AJ, Edwards RJ, Hughes LO, Berry C, Oldroyd KG; PRAMI Investigators. Randomized trial of preventive angioplasty in myocardial infarction. N Engl J Med. 2013;369:1115-23.

25. Gershlick AH, Khan JN, Kelly DJ, Greenwood JP, Sasikaran T, Curzen N, Blackman DJ, Dalby M, Fairbrother KL, Banya W, Wang D, Flather M, Hetherington SL, Kelion AD, Talwar S, Gunning M, Hall R, Swanton H, McCann GP. Randomized trial of complete versus lesion-only revascularization in patients undergoing primary percutaneous coronary intervention for STEMI and multivessel disease: the CvLPRIT trial. J Am Coll Cardiol. 2015;65: 963-72.

26. Engstrøm T, Kelbæk H, Helqvist S, Høfsten DE, Kløvgaard L, Holmvang L, Jørgensen E, Pedersen F, Saunamäki K, Clemmensen P, De Backer O, Ravkilde J, Tilsted HH, Villadsen AB, Aarøe J, Jensen SE, Raungaard B, Køber L; DANAMI-3_PRIMULTI Investigators. Complete revascularisation versus treatment of the culprit lesion only in patients with ST-segment elevation myocardial infarction and multivessel disease (DANAMI-3-PRIMULTI): an open-label, randomized controlled trial. Lancet. 2015;386:665-71. 27. Smits PC, Abdel-Wahab M, Neumann FJ, Boxma-de Klerk BM, Lunde K, Schotborgh CE, Piroth Z, Horak D, Wlodarczak A, Ong PJ, Hambrecht R, Angerås O, Richardt G, Omerovic E; Compare-Acute Investigators. Fractional Flow Reserve-Guided Multivessel Angioplasty in Myocardial Infarction. $N$ Engl J Med. 2017;376:1234-44.

28. Lee HJ, Song YB, Hahn JY, Kim SM, Yang JH, Choi JH, Choi SH, Choi JH, Lee SH, Gwon HC. Multivessel vs single vessel revascularization in patients with non-ST segment elevation acute coronary syndrome and multivessel disease in the drug-eluting stent era. Clin Cardiol. 2011;34:160-5.

29. Thiele H, Akin I, Sandri M, Fuernau G, de Waha S, MeyerSaraei R, Nordbeck P, Geisler T, Landmesser U, Skurk C, Fach A, Lapp H, Piek JJ, Noc M, Goslar T, Felix SB, Maier LS, Stepinska J, Oldroyd K, Serpytis P, Montalescot G, Barthelemy O, Huber K, Windecker S, Savonitto S, Torremante P, Vrints C, Schneider S, Desch S, Zeymer U; CULPRIT-SHOCK Investigators. PCI Strategies in Patients with Acute Myocardial Infarction and Cardiogenic Shock. N Engl J Med. 2017;377:2419-32.

30. Di Mario C, Mara S, Airoldi F, Imad S, Manari A, Petronio A, Piccaluga E, De Servi S, Ramondo A, Colusso S, Formosa A, Cernigliaro C, Colombo A, Monzini N, Bonardi MA. Single vs multivessel treatment during primary angioplasty: results of the multicentre randomized HEpacoat for cuLPrit or multivessel stenting for Acute Myocardial Infarction (HELP AMI) Study. Int $J$ Cardiovasc Intervent. 2004;6:128-33. 
31. Iqbal MB, Nadra IJ, Ding L, Fung A, Aymong E, Chan AW, Hodge S, Della Siega A, Robinson SD; British Columbia Cardiac Registry Investigators. Culprit Vessel Versus Multivessel Versus In-Hospital Staged Intervention for Patients With ST-Segment Elevation Myocardial Infarction and Multivessel Disease; Stratified Analyses in High-Risk Patient Groups and Anatomic Subsets of Nonculprit Disease. JACC Cardiovasc Interv. 2017;10: 11-23.

32. Aggarwal V, Rajpathak S, Singh M, Romick B, Srinivas VS. Clinical outcomes based on completeness of revascularisation in patients undergoing percutaneous coronary intervention: a metaanalysis of multivessel coronary artery disease studies. EuroIntervention. 2012;7:1095-102.

33. Shah R, Berzingi C, Mumtaz M, Jasper JB, Goswami R, Morsy MS, Ramanathan KB, Rao SV. Meta-Analysis Comparing Complete Revascularization Versus Infarct-Related Only Strategies for Patients With ST-Segment Elevation Myocardial Infarction and Multivessel Coronary Artery Disease. Am J Cardiol. 2016;118: 1466-72.

34. Zimarino M, Ricci F, Romanello M, Di Nicola M, Corazzini A, De Caterina R. Complete myocardial revascularization confers a larger clinical benefit when performed with state-of-the-art techniques in high-risk patients with multivessel coronary artery disease: a meta-analysis of randomized and observational studies. Catheter Cardiovasc Interv. 2016;87:3-12.
35. Ando T, Takagi H, Grines CL. Complete versus incomplete revascularization with drug-eluting stents for multi-vessel disease in stable, unstable angina or non-ST-segment elevation myocardial infarction: A meta-analysis. J Interv Cardiol. 2017;30:309-17.

36. Garcia S, Sandoval Y, Roukoz H, Adabag S, Canoniero M, Yannopoulos D, Brilakis ES. Outcomes after complete versus incomplete revascularization of patients with multivessel coronary artery disease: a meta-analysis of 89,883 patients enrolled in randomized clinical trials and observational studies. J Am Coll Cardiol. 2013;62:1421-31.

\section{Supplementary data}

Supplementary Table 1. Clinical outcomes in the total (non-propensity-matched) cohort.

Supplementary Table 2. All-cause mortality outcomes segregated into different time frames in the propensity-matched cohort $(n=1,480)$.

Supplementary Table 3. Secondary outcomes in the total (nonpropensity-matched) cohort $(n=2,598)$.

Supplementary Table 4. MACE rates of IR groups classified according to residual jeopardy score post PCI in the total (non-propensity-matched) cohort.

The supplementary data are published online at: www.asiaintervention.org 


\section{Supplementary data}

Supplementary Table 1. Clinical outcomes in the total (non-propensity-matched) cohort.

\begin{tabular}{|c|c|c|c|c|c|c|}
\hline \multirow[t]{2}{*}{ Outcome $(n=2,598)$} & \multicolumn{2}{|c|}{$\begin{array}{c}\text { Incomplete } \\
\text { revascularisation } \\
(n=744)\end{array}$} & \multicolumn{2}{|c|}{$\begin{array}{c}\text { Complete } \\
\text { revascularisation } \\
(\mathbf{n}=\mathbf{1 , 8 5 4})\end{array}$} & \multirow[t]{2}{*}{$\begin{array}{l}\text { Hazard ratio } \\
\text { (95\% CI) } \\
\text { (IR vs CR) }\end{array}$} & \multirow[t]{2}{*}{$p$-value } \\
\hline & n (\%) & $\begin{array}{c}\% \text { per } \\
\text { person/yr }\end{array}$ & n (\%) & $\begin{array}{c}\% \text { per } \\
\text { person/yr }\end{array}$ & & \\
\hline Total all-cause mortality & $37(5.0)$ & 1.1 & $36(1.9)$ & 0.4 & $2.61(1.65-4.13)$ & $<0.001$ \\
\hline Early mortality ( $\leq 30$ days) & $23(3.1)$ & 0.7 & $13(0.7)$ & 0.1 & $4.45(2.26-8.79)$ & $<0.001$ \\
\hline Late mortality ( $>30$ days) & $14(1.9)$ & 0.4 & $23(1.2)$ & 0.3 & $1.54(0.80-3.04)$ & 0.186 \\
\hline $\begin{array}{l}\text { Composite of all-cause } \\
\text { mortality, non-fatal MI, } \\
\text { repeat revascularisation and } \\
\text { angina (MACE) }\end{array}$ & $142(19.1)$ & 4.2 & $187(10.1)$ & 2.2 & $1.95(1.57-2.42)$ & $<0.001$ \\
\hline
\end{tabular}

CI: confidence interval; MACE: major adverse cardiovascular event; MI: myocardial infarction 
Supplementary Table 2. All-cause mortality outcomes segregated into different time frames in the propensity-matched cohort $(n=1,480)$.

\begin{tabular}{|c|c|c|c|c|c|c|}
\hline \multirow[t]{2}{*}{$\begin{array}{c}\text { Co-primary outcome } \\
(n=1,480)\end{array}$} & \multicolumn{2}{|c|}{$\begin{array}{c}\text { Incomplete } \\
\text { revascularisation } \\
(n=740)\end{array}$} & \multicolumn{2}{|c|}{$\begin{array}{c}\text { Complete } \\
\text { revascularisation } \\
(n=740)\end{array}$} & \multirow[t]{2}{*}{$\begin{array}{l}\text { Hazard ratio } \\
\text { (95\% CI) } \\
\text { (IR vs CR) }\end{array}$} & \multirow[t]{2}{*}{$p$-value } \\
\hline & n (\%) & $\begin{array}{c}\% \text { per } \\
\text { person/yr }\end{array}$ & n $(\%)$ & $\begin{array}{c}\% \text { per } \\
\text { person/yr }\end{array}$ & & \\
\hline Total all-cause mortality & $37(5.0)$ & 1.1 & $27(3.6)$ & 0.8 & $1.44(0.87-2.36)$ & 0.153 \\
\hline Early mortality ( $\leq 30$ days) & $23(3.1)$ & 0.7 & $8(1.1)$ & 0.2 & $2.90(1.30-6.49)$ & 0.009 \\
\hline Late mortality (>30 days) & $14(1.9)$ & 0.4 & $19(2.6)$ & 0.6 & $0.80(0.40-1.60)$ & 0.525 \\
\hline
\end{tabular}

CI: confidence interval 
Supplementary Table 3. Secondary outcomes in the total (non-propensity-matched) cohort $(n=2,598)$.

\begin{tabular}{|l|c|c|c|c|c|c|}
\hline Outcome & \multicolumn{2}{|c|}{$\begin{array}{c}\text { Incomplete } \\
\text { revascularisation } \\
(\mathbf{n = 7 4 4 )}\end{array}$} & $\begin{array}{c}\text { Complete } \\
\text { revascularisation } \\
(\mathbf{n = 1 , 8 5 4 )}\end{array}$ & $\begin{array}{c}\text { Hazard ratio } \\
\text { (95\% CI) } \\
\text { (IR vs CR) }\end{array}$ & p-value \\
\cline { 2 - 6 } & $\mathbf{n}(\mathbf{\%})$ & $\begin{array}{c}\mathbf{\%} \text { per } \\
\text { person/ } \\
\mathbf{y r}\end{array}$ & $\mathbf{n}(\mathbf{\%})$ & $\begin{array}{c}\text { \% per } \\
\text { person } \\
\text { /yr }\end{array}$ & & \\
\hline Non-fatal MI & $24(3.2)$ & 0.7 & $42(2.3)$ & 0.5 & $1.46(0.89-2.41)$ & 0.138 \\
\hline Repeat revascularisation & $60(8.1)$ & 1.8 & $97(5.2)$ & 1.2 & $1.59(1.15-2.19)$ & 0.005 \\
\hline Recurrent angina & $82(11.0)$ & 2.4 & $125(6.7)$ & 1.5 & $1.69(1.28-2.23)$ & $<0.001$ \\
\hline
\end{tabular}

CI: confidence interval; MI: myocardial infarction 
Supplementary Table 4. MACE rates of IR groups classified according to residual jeopardy score post PCI in the total (non-propensity-matched) cohort.

\begin{tabular}{|c|c|c|c|c|c|}
\hline \multirow{2}{*}{$\begin{array}{l}\text { Grade of IR } \\
\text { (jeopardy score) }\end{array}$} & \multirow{2}{*}{$\begin{array}{c}\text { No. of patients } \\
\text { (total } I R=744) \\
n(\%)\end{array}$} & \multicolumn{2}{|c|}{ MACE rate } & \multirow{2}{*}{$\begin{array}{c}\text { Hazard ratio } \\
\text { (95\% CI) } \\
\text { (IR vs CR) }\end{array}$} & \multirow{2}{*}{$\begin{array}{l}p \text {-value } \\
\text { (compared } \\
\text { to CR) }\end{array}$} \\
\hline & & $\mathrm{n}(\%)$ & $\begin{array}{c}\% \text { per } \\
\text { person/ } \\
\text { yr }\end{array}$ & & \\
\hline Mild IR $(<2.0)$ & $164(22.0)$ & $22(13.4)$ & 3.0 & $1.33(0.85-2.07)$ & 0.208 \\
\hline Moderate IR (2.1-5.0) & $461(62.0)$ & $93(20.2)$ & 4.5 & $2.03(1.60-2.60)$ & $<0.001$ \\
\hline Severe IR (>5.0) & $119(16.0)$ & $27(22.7)$ & 5.0 & $2.56(1.71-3.83)$ & $<0.001$ \\
\hline \multicolumn{6}{|c|}{$\begin{array}{l}\text { Intra IR group comparison ( } \boldsymbol{p} \text {-values): } \\
\text { Mild IR }(<2.0) \text { vs moderate IR }(2.1-5.0)=0.07 \\
\text { Mild IR }(<2.0) \text { vs severe IR }(>5.0)=0.02 \\
\text { Moderate IR }(2.1-5.0) \text { vs severe IR }(>5.0)=0.31\end{array}$} \\
\hline
\end{tabular}

CI: confidence interval; CR: complete revascularisation; IR: incomplete revascularisation; MACE: major adverse cardiovascular event; PCI: percutaneous coronary intervention 


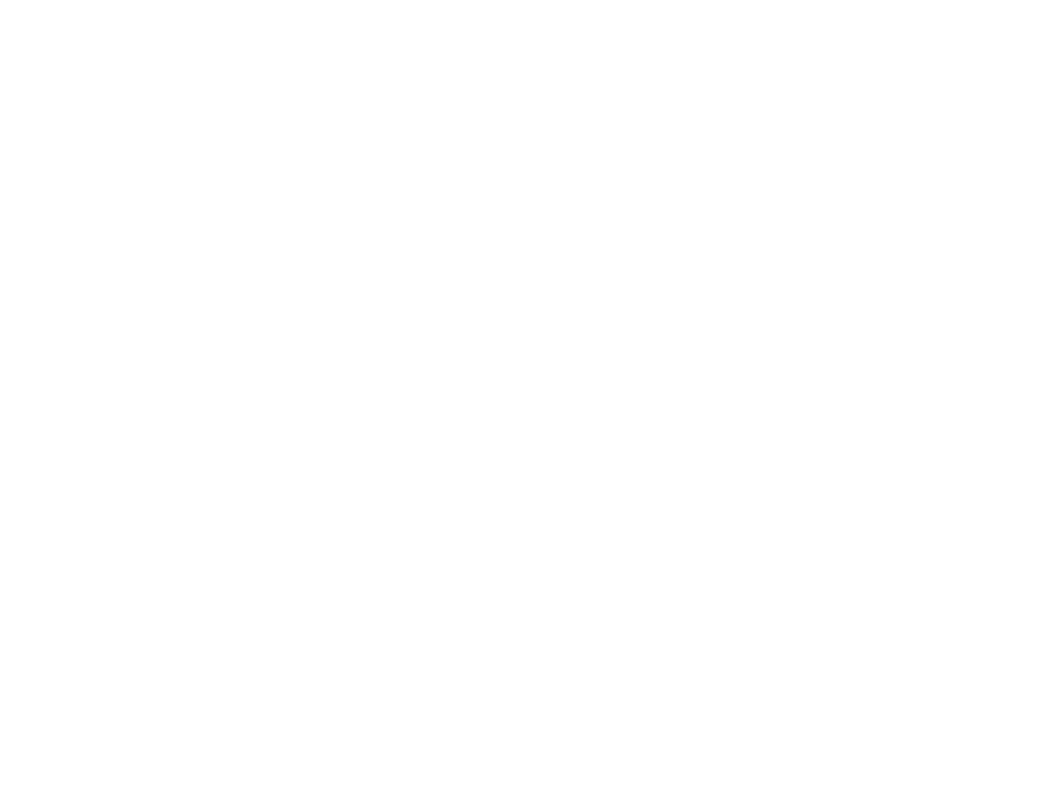

